\title{
Environmental Noise Pollution: Has Public Health Become too Utilitarian?
}

\author{
Alun Evans \\ Centre for Public Health, Queen's University Belfast, Belfast, UK \\ Email:a.evans@qub.ac.uk
}

How to cite this paper: Evans, A. (2017) Environmental Noise Pollution: Has Public Health Become too Utilitarian? Open Journal of Social Sciences, 5, 80-107. https://doi.org/10.4236/jss.2017.55007

Received: March 16, 2017

Accepted: May 9, 2017

Published: May 12, 2017

Copyright (C) 2017 by author and Scientific Research Publishing Inc. This work is licensed under the Creative Commons Attribution International License (CC BY 4.0).

http://creativecommons.org/licenses/by/4.0/

\begin{abstract}
Environmental noise pollution is an ever-increasing problem. The various sources: Aircraft, Road Traffic and Wind Farms are reviewed, but the latter source, because of the intrusive, impulsive and incessant nature of the sound emitted, is the major focus of this review. Wind turbines produce a range of sound but it is the Infrasound and low frequency noise which deserves special attention. Infrasound is considered to be below the range of human hearing so it is not measured in routine noise assessments in the wind farm planning process. There is, however, evidence that many can register it and a sizeable minority is sensitive, or becomes sensitised to it. The actual route of transmission still requires elucidation. The net effect of the entire range of noise produced is interference with sleep and sleep deprivation. Sleep, far from being a luxury is vitally important to health and insufficient sleep, in the long term, is associated with a spectrum of diseases, particularly Cardiovascular. The physiological benefits of sleep are reviewed, as is the range of diseases which the sleep-deprived are predisposed to. Governments, anxious to meet Green targets and often receiving most of their advice on health matters from the wind industry, must commission independent studies so that the Health and $\mathrm{Hu}-$ man Rights of their rural citizens is not infringed. Public Health, in particular, must remember its roots in Utilitarianism which condoned the acceptance of some Collateral Damage provided that the greatest happiness of the greatest number was ensured. The degree of Collateral Damage caused by wind farms should be totally unacceptable to Public Health which must, like good government, fully exercise the Precautionary Principle. The types of study which should be considered are discussed. Indeed, the father of Utilitarian Philosophy, Jeremy Bentham, urged that government policy should be fully evaluated.
\end{abstract}

\section{Keywords}

Environmental Noise Pollution, Wind Farms, Infrasound, Health Impacts, 
Public Health, Utilitarianism, Collateral Damage, Precautionary Principle

\section{Introduction}

There are a number of emerging threats to Public Health, and some of these can be directly ascribed to human activity, chief among which are Global Warming, air pollution and environmental noise pollution. This paper will concentrate on the issue of environmental noise pollution and examine how modern Public Health has lived up to its responsibilities in controlling it. Over a century ago, the Nobel Prize-winning microbiologist, Robert Koch, predicted [1] "One day man will have to fight noise as fiercely as cholera and pest (plague)." The accuracy of this prediction is attested to by the statement [2] from the United States Environmental Protection Agency that, "The over-all loudness of environmental noise has been doubling every ten years in pace with social and industrial growth, and, if allowed to continue unchecked, the cost of alleviating it in the future may be insurmountable." Perhaps surprisingly, this statement is more than 40 years old, yet the problem has been growing, unchecked, ever since.

From an evolutionary perspective, an awareness of sound is essential to alert us of incipient danger, but our aural acuity may have left us vulnerable to when it is present in excess. The earliest problems arose with the introduction of noisy industrial processes a couple of centuries ago, which induced deafness [3]. We are now being bombarded with noise pollution from diverse sources, which predisposes us to a range of diseases. Light radiation ranges from Ultraviolet to Infrared, and apart from its intensity, its wavelength will determine its effect on the receiver: typically different wavelengths in the Ultraviolet range have different effects on our skin [4]. Similarly, it is not just the amplitude of noise which brings health consequences, but also, its "frequency content" (considering the sound as a stimulus rather than how frequency in the audible range is perceived as pitch).

Sound is caused by a series of pressure pulsations, or more broadly, by changes in air pressure. The spectrum of sound [4] frequency ranges from $>1$ to more than 20,000 cycles per second or $\mathrm{Hz}$, with the range up to $20 \mathrm{~Hz}$ classified [5] as Infrasound, $>20-200 \mathrm{~Hz}$ as low frequency sound (the lowest note on a piano has a frequency of $33 \mathrm{~Hz}$ and Middle C, $262 \mathrm{~Hz}$ [6]), >200 - 20,000 Hz as the human auditory range, and $>20,000 \mathrm{~Hz}$ as Ultrasound. Strictly, pressure pulsations outside our auditory range cannot be described as sound but they are still able to exert an effect on us [5].

As with light, sound's effects on human health are not only determined by its intensity, or amplitude, but also by its frequency and the rate of change in amplitude. The term Infrasound is confusing, because how could sound which we are unable to hear have an effect on us? Perhaps a better way to look at it would be in terms of pressure pulsations. There is increasing evidence that Infrasound is perceived by the brain [7], and possibly by other sensory systems' vibratory 
receptors [8]: in the vestibular organ of balance, skin and joints, rather than by those transmitting auditory sensation [7]. Another problem with noise in the lower registers is that it persists longer, travels further and, thanks to diffraction, can turn corners [6].

This, from another evolutionary perspective, is no surprise. Many of our fellow mammals use Infrasound extensively for communication: e.g., giraffes, rhinoceroses, whales and elephants-the latter are capable of sensing distant thunderstorms, because of the Infrasound the storms emit, from over a hundred kilometres away [9], and set off in that direction in the knowledge that they will find water and green vegetation to consume. Humans carry a large range of genes which were acquired in our evolutionary past, but which are now redundant. Sometimes however, these are expressed, for example when, occasionally, someone grows a tail [10]. Olfactory receptor (OR) genes provide a good example of genes which humans possess but do not express. Mammals have over 1000 OR genes and these constitute the largest mammalian gene superfamily. In humans about $60 \%$ of these are pseudogenes and have been annulled through mutation [11]. In other primates, the pseudogene rate is about half of this. It is postulated that reduced chemosensory dependence in man drives this OR gene disruption. Individual differences in gene-expression might also explain why a small, but significant, proportion of the population may be more sensitive to the effects of Infrasound than others, and to noise in general [7]. An alternative hypothesis is that sufferers have been "sensitized" through past exposure [5], although both factors could contribute.

This review will concentrate on the adverse health effects associated with environmental noise, particularly those due to the Infrasound and low frequency noise emitted by industrial wind turbines. Some of the adverse health effects are due to sleep deprivation, and the evidence linking it to several diseases, particularly cardiovascular, will be discussed. The control of wind farm noise emissions, and its effectiveness, will be reviewed along with the appropriateness of the Guidelines governing noise limits, and where wind farms are sited. The studies which need to be mounted will then be described. The history of Public Health will be discussed, including the seminal role that Utilitarian Philosophy (the greatest happiness of the greatest number) played in its inception. The response of Public Health to new health threats will be evaluated in the light of the concepts of Collateral Damage and the Precautionary Principle. The overall aim is to evaluate the adverse health effects of industrial wind turbines and the adequacy of the Public Health response to the problems arising. In particular, the adequacy of the protection of the Health and Human Rights of rural citizens whose health is compromised by wind turbines will be scrutinized.

\section{Literature Review}

\subsection{Extent of the Problem}

The problem of noise pollution has been justly highlighted in two recent World Health Organisation reports. The first of these, entitled 'Night Noise Guidelines 
for Europe', stated [12] that “... environmental noise is emerging as one of the major Public Health concerns of the twenty-first century." It observed that, "Many people have to adapt their lives to cope with the noise at night," and that the young and the old are particularly vulnerable. This is because hearing in young people is more acute and, in older people, a loss of hearing of higher sound frequencies renders them more susceptible to the effects of low frequency noise [13]. A more recent World Health Organisation report calculated [14] that more than a million healthy life years (Disability Adjusted Life Years) are lost due to environmental noise annually in western EU member states. The vast bulk of these are lost because of noise-induced sleep disturbance, followed by 'Annoyance.' This is a construct assembled from subjects' responses to a questionnaire, where subjects are asked to indicate their 'Level of Annoyance' on a scale [15]. Annoyance is a common finding reported in a population exposed to environmental noise. It is difficult to define accurately, but one authority maintains that it can result from noise interfering with daily activities, feelings, thoughts, sleep or rest, and might be accompanied by negative responses, such as anger, displeasure, exhaustion and stress-related symptoms [16]. It clearly is not a trivial state.

Sleep disturbance is serious if it leads to sleep deprivation [17], which is associated with a gamut of Cardiovascular Diseases (CVD), obesity, diabetes, and poor memory consolidation [1]. In an up-to-date meta-analysis of 160,867 subjects, in whom 11,702 cases occurred, insomnia symptoms were shown to be significantly associated with the risk of cardio-cerebral vascular events [18]; and even some cancers [19]. On top of this, inadequate sleep in children is associated with impaired memory and learning, poor cognitive function, mental health disorders, and obesity [20]. The mechanism for this is not well understood but it may be connected to higher levels of a cannabis-like chemical found in individuals who are deprived of sleep [21]. The latter is of concern because it tends to sow the seeds for diabetes and CVD in later life.

\subsection{Importance of Sleep}

There is an ever-mounting volume of research to show that sleep is essential for the brain and the physiological well-being of the entire body. Sleep deprivation interferes with learning, causing memory impairment because memory is laid down and reinforced during both the Slow Wave and Rapid Eye Movement phases of sleep. In mice, it has been shown that sleep plays a key role in promoting learning-dependent synapse formation and maintenance on selected dendritic branches, which contribute to memory storage [22]. There are a number of other adverse effects associated with sleep deprivation. Tired individuals are more likely to have road traffic accidents and injure themselves while operating machinery. During sleep, neurotoxins are removed from the brain [23]. Lately, an association between sleep deprivation and loss of brain volume has been demonstrated [24]. This study was based on serial MRI scans carried out in 147 community-dwelling adults. In addition, it has been demonstrated [25] that 
various inflammatory biomarkers are affected by sleep deprivation.

Sleep deprivation produced experimentally also very rapidly alters the expression in a wide range of genes, involving several body systems [26] [27]. This could explain the links between sleep deprivation and CVD where the putative intermediate risk factors include blood pressure, clotting factors, blood viscosity, and blood lipids and glucose [1]. The cardiovascular effects of environmental noise exposure have been reviewed recently in studies carried out in 11 countries. These compared aircraft, road and railway sources of noise: aircraft noise was identified as the most highly annoying, and railways the least [1]. It is unclear as to which frequencies are contributing most because very often the full acoustic spectrum is not assessed. Jet aircraft, in particular, produce Infrasound and low frequency noise in abundance, so people dwelling near airports suffer adverse health effects [28] [29].

Why has environmental noise pollution become such a problem? Air and road traffic have increased and industrial installations have tended to get bigger. There are noise limits set, but they may not always be enforced. The other aspect, which should be of great concern to Public Health, is that the cut-points established as safe for any factor whose risk is continuously distributed, are nearly always set too high-e.g., blood pressure and LDL cholesterol-and subsequently have to be revised downwards. Asbestos is a prime example, with the permitted level of asbestos being successively reduced over many years [30] until its use was banned in most developed countries. Airports invariably have night time restrictions on flying and road traffic noise tends to be less at night. Wind farms emit noise, sometimes for days on end, and this is a problem because they are being constructed in rural areas where background noise is low. It is a particular problem at night, because Infrasound persists long after the higher frequencies have been dissipated [6]. This paper will concentrate on the health effects of wind turbine noise, which has been shown [31] to be particularly troublesome because of its impulsive, intrusive and incessant nature.

\subsection{Health Effects of Wind Turbine Noise}

The major adverse health effects caused by wind turbines seem to be due to sleep disturbance and deprivation, with the main culprits identified as loud noise in the auditory range and low frequency noise, particularly Infrasound. This is inaudible in the conventional sense, and is propagated over large distances and penetrates the fabric of dwellings, where it may become amplified by resonance. A report [32] commissioned by the Scottish Government, which is investing in wind energy to a heroic degree, grudgingly accepts that wind turbine noise interferes with sleep. A recent Swedish study, conducted [33] on healthy volunteers in a sleep laboratory, has shown that the noise produced by wind turbines, particularly low frequency band amplitude modulation, is disruptive to sleep. This was indicated by an increase in electro-physiological awakenings, lighter sleep with more wakefulness, and reduced deep sleep and Rapid Eye Movement sleep. 
A recent review identified [34] 146 potential papers assessing the effects of wind turbine noise, and after applying stringent criteria, came up with a shortlist of 18 , of which eight were included in a meta-analysis. All studies were crosssectional and a meta-analysis of six of these $(n=2364)$ revealed that the odds of being annoyed are significantly increased by wind turbine noise (OR: 4.08; 95\% CI: 2.37 to $7.04 ; \mathrm{p}<0.00001)$. The odds of sleep disturbance were also significantly increased with greater exposure to wind turbine noise (OR: $2.94 ; 95 \% \mathrm{CI}$ : 1.98 to 4.37 ; $<0.00001)$. Four studies reported that wind turbine noise significantly interfered with Quality of Life. Furthermore, the visual perception of wind turbine generators was associated with a greater frequency of reported negative health effects. Visual perception and sound emissions (effects of emissions after propagation on the environment) are directly related to distance so studies need to carefully differentiate the two sources of annoyance to ensure that each is properly assessed.

Sleep deprivation has also been shown [35] to be associated with heart failure in the HUNT Study. The data are quite robust as they are based on 54,279 Norwegians free of disease at baseline (men and women aged 20 - 89 years). A total of 1,412 cases of heart failure developed over a mean follow-up of 11.3 years. A dose-dependent relationship was observed between the risk of disease and the number of reported insomnia symptoms: i) difficulty in initiating sleep; ii) difficulty in maintaining sleep; and iii) lack of restorative sleep. The Hazard Ratios were " 0 " for none of these; " 0.96 " for one; " 1.35 " for two; and, " 4.53 " for three; this achieved significance at the $2 \%$ level. This means that such a result could occur once by chance if the study were to be repeated 50 times. Significance is conventionally accepted at the $5 \%$ level.

Another important, recent study is MORGEN, which followed [36] nearly 18,000 Dutch men and women, free of CVD at baseline, over 10 - 14 years. In this period there were 607 events: fatal CVD, non-fatal Myocardial Infarction and Stroke. Adequate sleep, defined as at least seven hours a night, was a protective factor which augmented the benefits conferred by the absence of four traditional cardiovascular risk factors. For example, the benefit of adequate sleep equalled the protective contribution of not smoking cigarettes. Given that cigarette smoking is such a potent risk factor for CVD, this result is striking. The findings built on earlier ones from the MORGEN study [37]. It seems that adequate sleep is important in protecting against a range of CVDs which result when arteries of different sizes are compromised: large (coronary, cerebral) arteries in heart attacks and stroke, small arteries (arterioles) in heart failure. The mechanisms are obscure, but it is known, for example, that exposing mice to stress activates [38] hematopoietic stem cells, i.e. affects the immune system and accelerates atherosclerosis.

All of these studies share the weakness that they are "observational" as opposed to "experimental" and, as such, their results do not constitute "proof". The results from the experimental study of sleep deprivation of fairly short durations [26], which affected the expression of a large range of genes, sheds light on the 
"Wind Turbine Syndrome (WTS)", a cluster of symptoms which includes sleep disturbance, fatigue, headaches, dizziness, nausea, changes in mood and inability to concentrate [39]. In this condition, Infrasound is a likely causal agent. Another report from HUNT has examined insomnia in almost 25,000 persons and has demonstrated [40] it to be a robust risk factor for incident physical and mental disease, which included several features of WTS.

This group has now shown, in another small intervention study, that mistimed sleep desynchronized from the central circadian clock has a much larger effect on the circadian regulation of the human transcriptome (i.e., a reduction in the number of circadian transcripts from $6.4 \%$ to $1 \%$ and changes in the overall time course of expression of $34 \%$ of transcripts). This may elucidate the reasons for the large excess of cardiovascular events associated with shift work [27]. The results demonstrate that any interference in normal sleeping patterns is inimical to cardiovascular health.

The old admonition that "What you can't hear won't harm you" sadly isn't true. It is now known [41] that the organ of Corti in the cochlea (inner ear) contains two types of sensory cells: one row of inner hair cells which are responsible for hearing; and three rows of outer hair cells which are more responsive to low frequency sound. Another function of the outer hair cells is that, due to their extensibility, they can modify the sensitivity of the cochlea. This has relevance to low frequency hearing and also to detecting higher frequencies which are amplitude-modulated at lower, if not infrasonic, frequencies. The Infrasound produced by wind turbines is transduced by the outer hair cells and transmitted to the brain by Type II afferent fibres. The purpose is unclear as it results in sleep disturbance. This may well be the group which is also liable to travel sickness, which is a sizeable proportion of the population. Schomer and his colleagues have since advanced [42] the theory that as wind turbines increase in size they increasingly emit Infrasound with a frequency below $1 \mathrm{~Hz}$ (CPS). Below this frequency the otoliths in the inner ear respond in an exaggerated way in a susceptible minority who will suffer symptoms of WTS. Previously it was thought that the brain was only under the control of electrical and biochemical stimuli, but there is new evidence [43] that it is sensitive, in addition, to mechanical stimuli.

There were important studies carried out in the 1980s which appear to have been forgotten and which give a clue to the mechanisms involved. Danielsson and Landström carried out [44] a study in 20 healthy male volunteers who were bombarded with Infrasound for varying periods. Just 30 minutes' bombardment with $125 \mathrm{~dB}$ at $16 \mathrm{~Hz}$ resulted in a mean $8 \mathrm{~mm}$ increase in diastolic blood pressure. On the other hand, systolic BP was not affected, whereas the Pulse Pressure decreased. This could have important effects in those exposed to environmental Infrasound, for although the intensity may not be profound, chronic exposure might raise blood pressure a little. From a population perspective, this could raise the burden of CVD. Scientists at the University of Toronto Institute for Aerospace and the University of Waterloo found [45] variability in response in 
volunteers exposed to Infrasound under laboratory conditions using Infrasound of $8 \mathrm{~Hz}$. The adverse responses of some individuals closely resembled motion sickness. They postulated that individual differences in the reaction to Infrasound might be explained by variability of inner-ear structure or central adaptive mechanisms.

As far back as 1996, the International Standards Organisation acknowledged [46] that motion sickness arises from low frequency oscillatory motion below 1 Hz. The report cites: “...a range of microscopic organs (mechano-receptors) distributed in the living tissues throughout the body that variously signal changing pressure, tension, position, vibratory motion, etc." This is highly intriguing as it seems extremely plausible that the same effect obtains for Infrasound in the same frequency range and this requires urgent clarification. Indeed, the incidence of motion sickness can be predicted from the magnitude, frequency, and duration of vertical oscillation [47]. There is also mounting evidence that jet engine Infrasound can induce Vibro-acoustic Disease [48]. It is recognized [49] that around 15\% - 20\% of individuals are seriously affected by the Infrasound and low frequency noise produced by aircraft, particularly jets.

A recent economic assessment of US environmental noise as a cardiovascular health hazard suggested that a reduction of $5 \mathrm{~dB}$ would reduce hypertension by $1.4 \%$ and coronary heart disease by $1.8 \%$, with an annual economic benefit of USD3.9 billion. The threshold for the noise-exposed group was $>55 \mathrm{dBA}$ LDN, though there is evidence in the literature that there may be important impacts at even lower levels of noise exposure [50]. Invariably in assessing noise exposure the average sound levels are assessed, whereas it may be that it is the peaks of sound which do the damage. In a study of seals kept in captivity, it was shown [51] that repeated elicitation of the acoustic startle reflex led to sensitization, subsequent avoidance behavior and induced fear conditioning. The data indicated that repeated startling by anthropogenic noise sources might have severe effects on long-term behavior.

An Iranian paper has lately reported [52] sleep disturbance in wind turbine workers, 53 of whom fell into three groups: mechanics, security staff and officials. The results showed that there was a positive and significant relationship between age, workers' experience, equivalent sound level, and the severity of sleep disorder. When age was constant, sleep disorders increased by $26 \%$ for each $1 \mathrm{~dB}$ increase in equivalent sound level. In situations where the equivalent sound level was constant, an increase in sleep disorder of $17 \%$ occurred for each year of work experience. There was a difference in sound exposure between the different occupational groups: the effect of noise in mechanics was 3.4 times greater than in the security group and about 6.5 times greater than in the official group. Sleep disorder caused by wind turbine noise was almost twice as high in the security group in comparison to the official group. It was concluded that the noise generated by wind turbines has health implications for everyone exposed to it.

In a study reported [53] from Japan, 15 subjects were experimentally exposed 
to various sound stimuli, including recorded aerodynamic noise and Infrasound, along with synthetic periodic sound, and were evaluated by electroencephalography. The induced rate of alphal rhythm decreased when the test subjects listened to all the sound stimuli and decreased further with reducing frequency. In particular, the induced rate of alphal rhythm, when the sound stimulus lay in the frequency band of $20 \mathrm{~Hz}$, produced the lowest rate of all. It was concluded that the subjects cannot relax comfortably when exposed to Infrasound.

The European Metrology Research Programme (EMRP) has now established that everyone, at least all 16 of the healthy 18 - 25-year-old volunteers studied, can perceive Infrasound down to $8 \mathrm{~Hz}$ [54]. This was the lowest frequency investigated and it is likely that even lower frequencies can be perceived. 'Perception' was assessed using functional magnetic resonance imaging (fMRI) and a significant response was detected which was localized within the auditory cortex and which was present down to $8 \mathrm{~Hz}$. The signal strength of the blood-oxygen-level dependent (BOLD) signal showed a minimum at $20 \mathrm{~Hz}$, so a further investigation of BOLD-signal's dependence on the loudness was carried out. A decreasing dynamic range of hearing in this frequency range was noted, accompanied by the finding that even sound signals with sound pressure levels only slightly above the threshold will be registered as annoying.

Several details in the brain imaging results suggested that, at frequencies around about $20 \mathrm{~Hz}$, the perception mechanism might change or is realized by a combination of different processes. One hypothesis is that a somatosensory excitation of the auditory cortex contributes at these frequencies [54]. Thus, the idea is floated that we are perceiving Infrasound directly through our body surface. This fits in with the concept of the vibration of body structures espoused by Persinger [6]. In the Cape Bridgewater study, in which turbines were intermittently turned on and off, the subject who could best predict whether or not the rotors were in motion or not was profoundly deaf [55].

The latest EMRP study conducted on 14 subjects has demonstrated [56], using fMRI, that Infrasound of $12 \mathrm{~Hz}$ administered at sound pressure levels just below the hearing threshold can induce changes in neural activity across several brain regions. Some of these regions are known to be involved in auditory processing, while others are recognized as playing key roles in emotional and autonomic control. Paradoxically, these effects were not observed when subjects were exposed to Infrasound of $12 \mathrm{~Hz}$ above the hearing threshold, because, apparently, the brain can adjust to it. These findings provide intriguing evidence that continuous exposure to subliminal Infrasound may be harmful to the human brain. Such physiological or even psychological effects could be mediated via a subconscious processing route. The transient up-regulation of these brain regions in response to Infrasound at this level may therefore reflect an initial stressor response, with symptoms becoming established through constant exposure.

The EMRP authors observe [56] that a large part of the Infrasound that we are exposed to in our daily environment is produced by continuous sources such as wind-turbines and traffic. They argue that it is these sources of constant and 
subtle Infrasound, which may not attain a level exceeding the threshold of perception, which exert influences on the nervous system. Thus it seems that low levels of Infrasound really are capable of getting in 'under the radar'. It is this very level of Infrasound which authorities such as Leventhall state cannot harm you and which WHO dismisses as having no physiological or psychological effects [56].

In addition, wind turbines can, and do, cause accidents by collapsing, blade snap, ice throw, and even going on fire. They induce stress and psychological disorder from shadow flicker, which also has implications for certain types of epilepsy and autism. Even the current planning process, with its virtual absence of consultation, is stress inducing, as is the confrontation between landowners, who wish to profit from erecting turbines, and their neighbours, who dread the effects on their health. Finally, wind turbines considerably reduce the value of dwellings nearby and this has a negative long-term effect on their owners' and their families' health [57]. On top of this, increasing numbers of families will be driven into fuel poverty by spiralling electricity costs which are subsidizing wind energy.

\subsection{Controlling Wind Farm Noise}

Another aspect is that the instruments and methods used to assess the cut-points may be inappropriate or inaccurate. The United Kingdom's Batho Report of the Noise Review Working Party in 1990 identified [58] low frequency noise as having a serious effect on those exposed to it. It also commented that the use of the A-weighted scale to assess low frequency noise was not appropriate. The Aweighted scale was in fact designed to reflect the normal human auditory range for many common urban/suburban noise sources. The rationale for this derives from work published by Fletcher and Munson [59] in 1933 using pure tones and ear-occluding headsets (headphones) with the object of increasing the distance over which the human voice could be transmitted by telephone wire. The tests were therefore conducted in a setting intended to mimic the use of an ear-occluding headset, i.e., a telephone. The use of occluded ears and pure tones is a totally artificial situation and not directly comparable to "free-field" hearing. Normal hearing occurs in "free field", without occluding the ear, and in the presence of many other background sounds.

When a noise emits more Infrasound and low frequency energy than usual, the use of A-weighted thresholds and measurements is not protective. If unweighted Infrasound measurements had been used to investigate Sick Building Syndrome, its generally accepted cause, Infrasound and low frequency rumble, could have been detected much earlier [60]. It has been known for a long time that fans turning inside buildings can make people sick [61] and there are questions remaining about the effects of even larger fans turning outside buildings $[60]$, i.e. wind turbines.

The problem of Infrasound and low frequency noise was well-recognized in a Report by Casella Stanger, commissioned by DEFRA in 2001 [62] with the 
statement that: "It should not be regarded as formal guidance from DEFRA", but what is unclear is just when this advice was added. The Report advises, "For people inside buildings with windows closed, this effect is exacerbated by the sound insulation properties of the building envelope. Again, mid and high frequencies are attenuated to a much greater extent than low frequencies." It continued: "As the A-weighting network attenuates low frequencies by a large amount, any measurements made of the noise should be with the instrumentation set to linear." It drew heavily upon the Batho Report of 1990 [58]. In fact, these problems had already been elucidated and the measurement issues addressed in a trio of papers by Kelley and his colleagues in the 1980s [63] [64] [65]. Kelley and his colleagues began investigating a single turbine at Boone, North Carolina, in late 1979 when around $12 \%$ of families within $3 \mathrm{~km}$ where impacted by noise emissions from a single wind turbine. The 237-ft high $2 \mathrm{MW}$ turbine with four cylindrical legs was perched "atop Howard's Knob" and the passage of the rotors past the legs caused low frequency pressure pulsations to be propagated into the structures in which the complainants lived. The situation was aggravated further by a complex sound propagation process controlled by terrain and atmospheric focusing. The report runs to 232 pages and is certainly comprehensive [64].

The annoyance was described as an intermittent "thumping" sound accompanied by vibrations. A "feeling" or "presence" was described, felt rather than heard, accompanied by sensations of uneasiness and personal disturbance. The "sounds" were louder and more annoying inside the affected homes. Some rattling of loose objects occurred. In one or two instances, structural vibrations were great enough to cause dust to fall from high ceilings and create an additional nuisance. The noise was found to be more persistent and perhaps more severe at night. Moreover, it was noted as being worse in small rooms, usually bedrooms. The impulsiveness of the emitted low frequency acoustic radiation was identified as a major factor in determining not only the level of potential annoyance to residents within a structure, but perception as well. Various recommendations were made concerning noise reduction [65].

Kelley and his colleagues' research was promoted at conferences on wind turbine noise but seems to have been ignored or forgotten, so the problem continues to be seriously underestimated. When measured using a tool which can detect it, levels of Infrasound and low frequency noise are disturbingly high, with 'sound pressure levels' greater than previously thought possible [66]. It has also been demonstrated that infrasonic noise interferes with the micro-mechanics of the human inner ear [67].

In February 2003, the UK Department of Trade and Industry launched [68] 'Our Green Energy Future,' which committed the country to wind energy. Despite the existence of the Casella Stanger Report warning about Infrasound and low frequency noise and its caveats about how it should be assessed, the Government used another Report dated May 2003 which told a rather different story [5]. Although a lot more comprehensive than the Casella Stanger Report [62], it 
was aligned with the ETSU-R-97 recommendations [69] (see below). This is all rather reminiscent of the allegedly "Dodgy Dossier" which the then Prime Minister, Tony Blair, used to launch the UK's involvement in the Iraq war the same year. It was published by the same Government Department which had published the Casella Stanger Report two years before. This looked remarkably like the Government commissioning the report which would facilitate its energy policy.

The Report by Leventhall [5], who has acted as a noise consultant to wind companies, actually states, "The effects of Infrasound or low frequency noise are of particular concern because of its pervasiveness due to numerous sources, efficient propagation, and reduced efficiency of many structures (dwellings, walls, and hearing protection) in attenuating low frequency noise compared with other noise," but it seems that this was the work of a co-writer. Despite this, the message conveyed is that modern wind turbines are not an important source of Infrasound and the use of A-weighting is entirely adequate. The report also states that "Infrasound exposure is ubiquitous in modern life." This may be so, but Persinger makes [6] the point that naturally occurring Infrasound, including that produced within our own bodies, is random, whereas wind turbine Infrasound is pulsatile; and it is this quality which causes health problems.

The message concerning the appropriateness of using A-weighting in assessing sound has recently been reasserted by Leventhall and three of his fellow acousticians [70]. This was in spite of the fact that three of them had previously recommended, in joint and separate statements and publications, that Infrasound should be viewed as a source of adverse effects.

\subsection{Wind Farm Guidelines}

In the UK, the construction of wind farms is predicated on ETSU-R-97 which was organized by the wind industry, ably assisted by acousticians and others associated with the industry, without a single Sleep Physician, in 1996-1997 [69]. The authors state in the executive summary: "This document describes a framework for the measurement of wind farm noise and gives indicative noise levels thought to offer a reasonable degree of protection to wind farm neighbors, without placing unreasonable restrictions on wind farm development or adding unduly to the costs and administrative burdens on wind farm developers or local authorities." Despite these lofty ideals, a recent review observed [71]: "Exposure to wind turbines does seem to increase the risk of annoyance and self-reported sleep disturbance in a dose-response relationship. There appears, though, to be a tolerable level of around $\mathrm{L}_{\text {Aeq }}$ of $35 \mathrm{~dB}$. " This is about $6 \mathrm{~dB}$ less than the permitted ETSU-R-97 night time level, implying a doubling of the setback (assuming a decay of noise level of $6 \mathrm{~dB}$ per doubling of distance). The ETSU-R-97 recommendations were based on the turbines of the mid 1990s which had a hub-height of $32 \mathrm{~m}$, whereas today's turbines are several times taller with blades that are much longer and more flexible.

Applying the ETSU-R-97 methodology, which is still in force, setback dis- 
tances for human habitation from modern 2.5 - $3 \mathrm{MW}$ turbines are in the region of $500-600 \mathrm{~m}$. There are good reasons for believing that these setbacks are woefully inadequate. A 2013 Marshall Day Acoustics 'Examination of the significance of noise in relation to onshore wind farms' [72], commissioned by the Sustainable Energy Authority of Ireland, reproduces a graph from the Møller and Pedersen paper of 2011 [73]. This shows how the noise emitted by a turbine increases with size. In fact, a doubling in turbine generating capacity from $1 \mathrm{MW}$ to $2 \mathrm{MW}$ may result in slightly more than a doubling of the overall A-weighted sound power level, that is, an increase of more than $3 \mathrm{~dB}$. Also, for a range of turbines with the same power generating capacity, sound level output can vary by several decibels. Moreover, it was noted that while audible sound increased with increasing turbine size, the emission of low frequency sound was disproportionally greater. Shifting the acoustic energy into the lower frequencies renders A-weighted measurements and guidelines even less applicable. These data applied to turbines up to $3.6 \mathrm{MW}$, but are expected to apply to even larger ones. It was noted that the relationship is not necessarily statistically significant, which may well be the case, but it is almost certainly biologically significant.

In Ireland, the current setback, introduced in 2006, is a mere $500 \mathrm{~m}$, although there have been repeated promises by government to increase it [74]. There are also concerns about the use of average noise levels as these smooth out the peaks. It is these sound pressure peaks which may be sensitizing people to noise, as has been shown in the case of seals [51]. Averaging only serves to conceal important characteristics which exert adverse effects on living things.

In 2008, the distinguished American acoustic engineers, George Kamperman and Richard James, posed [75] the question: "What are the technical options for reducing wind turbine noise emission at residences?" They observed that there were only two options: i) increase the distance between source and receiver; or ii) reduce the source sound power emission. They added that neither solution is compatible with the objective of the wind farm developer to maximize the wind power electrical generation within the land available. They also highlighted the fact that Vestas' employees are not allowed to go within $400 \mathrm{~m}$ of a turbine while it is in motion. Turbines can produce Infrasound even when they are not running when wind excites the tower and blades. Long-range measurements from two different wind farms over a distance of $80 \mathrm{~km}$ have shown that Infrasound below $6 \mathrm{~Hz}$ has a propagation loss approximating to $3 \mathrm{~dB}$ per doubling of distance [76].

Lastly, carpeting the Irish landscape with wind turbines has led to a proliferation in power lines which come with their own health risks. An association between living close to high voltage power lines and the development of childhood leukemia has been consistently observed [77]. Recent epidemiological studies are in agreement with earlier findings of an increased risk of childhood leukemia with estimated daily average exposures above 0.3 to $0.4 \mu \mathrm{T}$. Although no mechanisms have been identified and consequently causality cannot be ascribed [77], in view of its serious nature the association cannot simply be ignored. 


\subsection{What Studies Should be Mounted?}

Although the associations between noise pollution, particularly from Infrasound and low frequency noise, and ill health can be argued against, and there are gaps in our knowledge, there is sufficient evidence to cause grave misgivings about its safety. Further research, supported by adequate funding, remains necessary. Good and caring Government should entail acting with greater caution when its policies could jeopardize the Health and Human Rights of its people.

So what studies need to be mounted? Hessler and his colleagues, as well as upholding [70] the adequacy of A-weighting, pose the question: "Do wind turbines make people sick? That is the issue."

This paper, written by four "scientists in the wind turbine acoustical field" who "do not doubt for a moment the sincerity and suffering of some residents close to wind farms and other low frequency sources, and this is the reason all four would like to conduct, contribute or participate in some studies that would shed some light on this issue." This all sounds very laudable, but the basic contention of their paper is that there is no adverse human health effect from low frequency noise and Infrasound, provided that A-weighting is used to measure them and current guidelines are adhered to. What, precisely, qualifies them to pronounce on health issues is obscure.

They continue: "It must also be said that it is human nature to exaggerate grievances and that some qualitative measure must be made available to compensate affected residences." It is hard to assimilate the logic of this sentence, but the first part is clearly intended as an antidote to the residents' "sincerity and suffering" described earlier in the paragraph. It should be pointed out that babies, young children, and animals that are unable to "exaggerate grievances" are also seriously impacted when exposed to low frequency noise and Infrasound, eg badgers [78], pigs [79], crabs [80] and, perhaps, even plants [81]. The phrase "exaggerate grievances" is also redolent of accusing sufferers of hysteria, which is all rather cynical. A similar fate befell Myalgic Encephalomyelitis sufferers when they had their condition derisively dismissed as "Yuppie Flu", until in 2011, when it was finally accepted as a true disease entity and International Consensus Criteria were developed [82].

Some of the studies the "scientists" propose [70] are not particularly scientifically robust: e.g., National Surveys, collecting cross-sectional data which may reveal associations, which, no matter how strong, cannot establish causation, are slow, inconclusive and favor the status quo; and Noise Source Reduction, i.e. trying to reduce noise emissions from turbines, which seems welcome but oddly similar to the tobacco industry's attempts to reduce tar in tobacco while ignoring the fact that tobacco smoke contains a cocktail of noxious elements [83], as wind turbine noise certainly also does. For example, in addition to Infrasound, Amplitude Modulation related to wake interference between turbines [84] can effectively double the noise produced. This is particularly likely to occur when turbines are crowded too close together, which also reduces their output [85].

Some other suggestions are better such as Perception Testing to investigate 
whether receivers have the ability to detect a turbine's activity without actually seeing or hearing it. It seems that it is only a minority, albeit a significant one, which is impacted by it. Moreover, whichever pathway transmits Infrasound to the brain is immaterial as it is unquestionably registered there. As noted above, one person who is sensitive to feeling the pulsations has nerve deafness. Furthermore, published reports by acousticians who are sensitive to infrasonic pressure pulses should establish that people can feel them even when sound pressure levels are insufficient to achieve the threshold of audibility [86].

The Recommendation [70] concerning Simulation appears the most sensible, by duplicating and simulating low frequency noise and Infrasound with loudspeakers, and exposing volunteers to high and low levels, to establish threshold levels. This approach would be valid if the sound correctly reflects what is experienced by people exposed to wind turbine noise. Such is the nature of the pulsations that electronic systems employing loudspeakers cannot reproduce them accurately. This all begs the question as to why not carry out this study in the field and measure some hard endpoints?

As the authors point out: "Realistically, it is not even possible to answer the posed question to all parties' satisfaction with practical research. For examples, a direct link to adverse health effects from yesterday's tobacco and today's excess sugar can be denied forever, because any research that could actually prove a link to all parties would take longer than forever and would be totally impractical." Surely there is ample evidence that sugar consumption, as it is a rich source of calories, is associated with obesity? This, although arguably not a disease in itself, is a powerful marker for a range of diseases. In this sense obesity represents a strong "intermediate phenotype" lying on the physio-pathological pathway between health and disease. Similarly, in relation to tobacco, there are biomarkers which are elevated in people who smoke and which indicate an increased risk of lung and other associated cancers [83].

So, does Infrasound and low frequency noise emitted by wind turbines make people sick? The authors comment [70] that, "It is abundantly obvious that intense adverse response occurs at certain sites" but stop short of admitting that it does make people sick, despite their having investigated complaints reported to them by adversely affected citizens. The authors support wind energy: "Likewise, wind farm opponents must accept reasonable sound limits or buffer distance to the nearest turbine-not pie-in-the-sky limits to destroy the industry." This all depends on what is considered "reasonable."

It is abundantly clear that sound levels involve a similar, continuous increase in risk, in a similar way that the amount of tobacco smoked determines [81] the risk of lung cancer. That is why cut-points for the levels of sound permitted were established in an attempt to protect receivers. What we have learned about cutpoints in the past, for example from the asbestos scandal, is that, from the outset, cut-points are invariably placed too high and constantly need to be reduced [30].

In the late $18^{\text {th }}$ century, the great Scottish Anatomist, John Hunter, wrote to his protégé, Edward Jenner, asking him: "Why think? Why not do the experi- 
ment?" [87]. He was exhorting Jenner to measure the core temperature of a hibernating hedgehog. We all have remnants of the genes for hibernation but we don't express them [88]. Similarly, in common with some animals, we possibly all have the genes for reacting to Infrasound, but only some of us express them.

It would be perfectly feasible to mount an experiment, a randomized crossover trial, in which persons impacted by wind farm noise have their biomarker levels [25] [89] measured after standardized periods of exposure and non-exposure to wind turbine noise. In this way, each person would act as his or her own control. A well-devised trial could be of modest size, be cheap to conduct and deliver results relatively quickly. Assessment of the blood transcriptome [26] would increase the scope of such a trial, as would cortisol assessment [78]. This study could be augmented with the 'Simulation' study proposed by the authors to identify critical frequencies and sound levels if a test chamber and audio system can be devised which accurately reproduces the pulsations experienced in people's homes. Besides, the comparison of means makes for a more powerful statistical analysis. This sort of study will quickly indicate whether exposure to wind turbine noise is safe or not. It has a huge advantage over prospective studies which will take years to accumulate hard disease endpoints, as was the case with tobacco. For many people exposed to industrial wind turbines the question as to whether they can feel or otherwise sense them has already been answered. Could the reluctance of the wind industry to mount the appropriate studies be due to the worldwide spate of complaints from those exposed to wind turbine noise?

The Salford Report, again written [32] by a group of acousticians without any input from sleep experts, concluded that there is "... some evidence for sleep disturbance which has found fairly wide, though not universal, acceptance.” The increasing weight of evidence of sleep deprivation's association with several chronic diseases is totally ignored. The authors of the Report are at pains to deny any "direct" health effects. In terms of prevention, any differentiation between 'direct' and 'indirect' is irrelevant: in $271 \mathrm{BC}$, the Roman consul Manius Curius Dentatus ordered the construction of a canal (the Curiano Trench) to divert the stagnant waters surrounding the River Velino in Umbria over the natural cliff at Marmore, to produce Cascata delle Marmore [90]. Romans had an aversion to drinking stagnant water and went to great lengths to "drain the swamp" because they associated it with illness. In this case the stagnant water was only "indirectly causal" but was vital to the propagation of Malaria, and hence draining the swamp abolished Malaria locally.

Governments pursuing renewable energy targets must adhere to the Precautionary Principle (see below). They have a duty to commission appropriate studies to ensure that the health of their rural citizens is adequately protected. It might be assumed that the wind industry would have carried out these studies as part of its "due diligence", but, to date, no such studies have been forthcoming. 


\section{The Public Health Perspective}

\subsection{Public Health and Utilitarianism}

Public Health developed in different ways in different countries. In Europe, Johann Peter Frank's System einer vollstädigen medinischen Polizey was particularly influential [91]. Frank's epic work was published in six volumes between 1779 and 1817 and promoted the concept of "Medical Police". The word 'Police' here connotes public administration. It was taken up by Andrew Duncan (Senior) in the Edinburgh University Medical School, who published a "Memorial" in 1798 presenting an outline of what he saw as a comprehensive course of instruction in Medical Police [92]. The concept spread to Ireland, where Henry Maunsell was appointed as Professor of Political Medicine at the Royal College of Surgeons of Ireland in 1841 [93].

The concept was also adopted in England, where Edwin Chadwick wrote upon Preventive Police in 1829 [94]. Chadwick was a lawyer and "...'the bureaucratic radical'... disciple of the archutilitarian [sic] Jeremy Bentham," who in 1842 was to publish his famous Report on the Sanitary Conditions of the Labouring Population of Great Britain, which he wrote in his position as Secretary to The Poor Law Commissioners. As a young man, Chadwick was Bentham's assistant and he afterwards applied Bentham's Utilitarian principles to Public Health [95]. Chadwick's Report paved the way for the establishment of the General Board of Health in 1848, under the great Public Health Act [96]. Chadwick's work heading the Board strongly influenced the thinking of doctors such as John Simon, and this marks the birth of Public Health in England [96] and the Medical Officers of Health. Thus, in Britain, modern Public Health grew out of the Utilitarian philosophy, developed by Jeremy Bentham, which enshrined the ethos that a morally good action is one that helps the greatest number of people.

However, it now seems that economic growth, particularly during a recession, is such an important goal that other aspects, such as health, are seen as being of secondary importance. It is essential that Public Health should increase its vigilance; to do any less would be to betray its proud past.

\subsection{Collateral Damage}

In the United Kingdom in1853, a Vaccination Act was passed: it was a compulsory act which decreed that all parents had to have their infants vaccinated against Smallpox within three months of birth. It supplanted the permissive Vaccination Act of 1840, which simply hadn't worked. Although it was known that a small proportion of children would succumb to the effect of the vaccination, this was trifling in comparison to the number of deaths from Smallpox which would be prevented [97]. In effect, Public Health had accepted the principle of Collateral Damage, provided that the overall benefit was large and the damage was small. Eventually, by the 1970s, vaccination was phased out because as the eradication of Smallpox approached, vaccinia was claiming more lives than Smallpox was [98]. 


\subsection{The Precautionary Principle}

The problem is just how much Collateral Damage is acceptable? When the BSE epidemic emerged in the late 1980s, the Government insisted that, providing simple measures were applied, beef was perfectly safe. The Minister of Agriculture went public and was photographed administering a hamburger to Cordelia, his four-year-old daughter [99]. Instead of applying the Precautionary Principle (enabling rapid response in the face of a possible danger to human, animal or plant health) [100], which should have triggered primate feeding experiments, the Government decided to tough it out, apparently for the health of the Farming Industry rather than for the health of its citizens. It compromised by having neural tissue separated from meat, seemingly oblivious of the fact that nerves innervate muscle. In effect, the experiment was being carried out on an unsuspecting populace.

In 1996, the first vCJD cases were identified and epidemiologists predicted thousands of deaths. Public Health was remarkably quiet on the issue but, to date, the disease has only resulted in 177 deaths. The reason that it has not been higher lies in the fact that there is a very specific genetic element as to who will develop the disease. There were no long-term monitoring measures put in place, but ad hoc studies indicate that the number of people infected with abnormal prion protein may be in the region of 30,000 [101]. Although representing only a small proportion of the total population, it still lies uneasily with Utilitarian principles in that the level of possible Collateral Damage was unacceptably large.

A similar population experiment seems to be underway in terms of environmental noise pollution. Governments, faced with economic recession, have been keen to increase economic activity and meet Green targets. As a result, environmental noise has increased. Public Health must maintain its position as champion of the health of the public and not just slavishly back up government policy. How can it be that environmental noise pollution continues to escalate despite the very real adverse effects it exerts on human health? A recent report from the Royal Society of Public Health has placed stress [102] on the importance of sleep to health. This is all very well, but nowhere in the 30-page document is there a mention of the role of noise in disrupting sleep, in fact the word "noise" is completely omitted. Perhaps the Royal Society was anxious not to open the noise can of worms? In her 'Notes on Nursing' in 1859 [103], Florence Nightingale was not so squeamish, because when she extolled the importance of sleep to health, she was also attuned to the deleterious effects of noise: "Unnecessary noise...is the most cruel absence of care which can be inflicted either on sick or well."

As sleep deprivation is the most important health-damaging effect of environmental noise pollution, Public Health should be treating the matter very seriously. Indeed, the United Nations Committee Against Torture (UN CAT) has explicitly identified "sleep deprivation for prolonged periods" [104] as a method of torture. In 1978, in a case taken to Europe by the Irish Government, the British Government was found guilty of applying five techniques, including subjection to noise and deprivation of sleep [57]. These were used in Ulster to 'en- 
courage' admissions and to elicit information from prisoners and detainees. They amounted to humiliating and degrading treatment, i.e. torture. Although the judgment was afterwards overturned on appeal, and downgraded to inhuman or degrading treatment', the action is still alive. The case being taken by 'The Hooded Men' is being backed by the Irish Government [105]. This same Government, by its failure to revise the turbine setback guidelines, is imposing noise and sleep deprivation on its rural citizens.

\subsection{Public Health's Responsibilities}

When Public Health doctors are asked about possible health effects, they tend to dismiss the literature as either non-peer-reviewed, or if it is a review, non-systematic. If they want to read a comprehensive, thorough and systematic review, they should look no further than that by Punch and James [106]. The Public Health Agencies in the UK are now relying on a document published in April 2013 which is also not peer-reviewed [32]. As already mentioned, was written by a group of acousticians at the University of Salford, which begs the question as to why such a group was selected to pronounce on health issues. Since acousticians derive a significant proportion of their income from the wind industry, their scientific objectivity might be open to question. Similarly, if a profession which worked closely with the tobacco industry was asked to report on health, questions would be asked.

Recently, a Vestas PowerPoint presentation from 2004 has surfaced [107] demonstrating that Vestas knew over a decade ago that safer buffers were required to protect neighbors from wind turbine noise. They knew their pre- construction noise models were inaccurate and that "...we know that noise from wind turbines sometimes annoys people even if the noise is below noise limits." Similarly, we are repeatedly told that modern turbines are quieter and produce less Infrasound and low frequency noise, which in reality is the reverse of the case. Denmark has been in the vanguard of wind energy development and there is a Danish initiative entitled "WIND2050" [108]. This appears to seek to promote the interests of the wind industry, particularly through encouraging "Community Ownership" of wind farms. To enable this, the project is "mapping criticism", i.e. assembling maps to show where rural citizens have raised any objection to wind farm development. It seems analogous to tobacco companies keeping smoking cessation clinics under surveillance.

There has been a tendency for Public Health to toe the official line that wind farms are entirely safe. This is the message promulgated by the wind industry so Public Health should be evaluating the evidence more critically. If Public Health doctors actually visited the families who have been forced to abandon their homes they might demand to see the necessary studies conducted. They would learn that some of the worst affected are small children who are very often put in the smaller bedrooms which are worst impacted by noise [64]. There is also the intriguing possibility that if Infrasound is conducted through the skin [54], young children will receive a larger dose because their surface area is greater in 
relation to their volume in comparison to adults. This is why small children lose heat faster than adults.

To her credit, in 2014, one Irish Public Health doctor, the Deputy Chief Medical Officer, actually stated that while turbines do not represent a threat to Public Health, "there is a consistent cluster of symptoms related to living in close proximity to wind turbines which occurs in a number of people in the vicinity of industrial wind turbines" and that "These people must be treated appropriately and sensitively as these symptoms can be very debilitating" [109]. The Irish Wind Energy Association promptly rounded on her with the accusation of her "having focused on out-of-date information," but she stood her ground admirably.

In view of the foregoing considerations, and because Public Health's apparent official view is that there are no important health effects caused by exposure to wind turbine noise, a reappraisal of the evidence is overdue. Public Health doctors should be conducting focused epidemiological studies, but this is something that they haven't displayed much aptitude for of late. Apart from anything else, Public Health should be rigorously applying the Precautionary Principle or Primum non nocere (First, do no harm) ideal, putting monitoring and evaluation in place and then undertaking the appropriate studies. A recent review of peer-reviewed studies published between 2000 and 2015 concluded [110] that the estimated pool prevalence of high subjective annoyance was around $10 \%$. This figure is very close to that found by Kelley [64] and his colleagues cited above, although the true figure may well be higher. The authors observed that epidemiological research on low frequency noise is scarce and suffers from methodological shortcomings. They added that low frequency noise in the everyday environment is an issue which requires more research attention, particularly for people living in the vicinity of relevant sources.

Environmental noise pollution, particularly when it deprives people of sleep, is especially related to the development of CVD, as a recent paper concluded that: "... the public health impact of sufficient sleep duration, in addition to the traditional healthy lifestyle factors, could be substantial” [36]. Public Health must take its responsibilities seriously to protect the Health and Human Rights of all citizens. Despite a desire to meet various Renewable Energy targets, Government must ensure that the appropriate studies are undertaken in order to protect the sizeable minority of the exposed population which suffers adverse effects. In fact, Jeremy Bentham shrewdly anticipated the necessity for Government support for research in both theory and practice [111]. In the $19^{\text {th }}$ century, Public Health acted to protect the health of town dwellers, thrown together by the Industrial Revolution. People had moved from the country into towns where they were exposed to industrial pollution. We are now witnessing the reverse process, a second Industrial Revolution, in which large industrial machines are being imposed on rural dwellers, and Public Health must act to see that sufficient safeguards are put in place so that rural citizens' health is fully pro- 
tected.

As Bradford Hill observed [112] over half a century ago: "The lessons of the past in general health and safety practices are easy to read. They are characterised by empirical decisions, by eternally persistent reappraisal of public health standards against available knowledge of causation, by consistently giving the public the benefit of the doubt, and by ever striving for improved environmental quality with the accompanying reduction in disease morbidity and mortality". Quite so, it is high time that Public Health gave the public the benefit of the doubt.

\section{Conclusion}

So has Public Health become too utilitarian? All the available evidence indicates that an important minority of local inhabitants is severely impacted by noise emitted by wind farms sited too close to their homes. This degree of Collateral Damage is too large to accept in terms of Utilitarianism. Public Health must exercise the Precautionary Principle and retain as much independence from government as possible in assessing the health effects of national policies. The Health and Human Rights of rural-dwelling citizens are every bit as important as those of the rest of society. In fact, in terms of wind energy, the overall benefit is fairly modest [113] [114] and the adverse effect on people's health is far from small. It is essential that separation distances between human habitation and wind turbines are increased. There is an international consensus emerging for a separation distance of $2 \mathrm{~km}$; indeed some countries are opting for $3 \mathrm{~km}$ and more. Furthermore, the appropriate, focused studies should be undertaken as soon as possible.

\section{References}

[1] Münzel, T., Gori, T., Babisch, W. and Basner, M. (2014) Cardiovascular Effects of Environmental Noise Exposure. European Heart Journal, 35, 829-836. https://doi.org/10.1093/eurheartj/ehu030

[2] Meyer, A.F. (1971) EPA's Noise Abatement Program. United States Environmental Protection Agency, Washington DC.

[3] Basner, M., Babisch, W., Davis, A., et al. (2014) Auditory and Non-Auditory Effects of Noise and Health. The Lancet, 383, 1325-1332.

[4] Mead, M.N. (2008) Benefits of Sunlight: A Bright Spot for Human Health. Environmental Health Perspectives, 116, A160-A167.

[5] Leventhall, G. (2003) A Review of Published Research on Low Frequency Noise and Its Effects. Report for DEFRA.

[6] Persinger, M.A. (2014) Infrasound, Human Health, and Adaptation: An Integrative Overview of Recondite Hazards in a Complex Environment. Natural Hazards, 70, 501-525.

[7] Salt, A. and Lichtenhan, J.T. (2014) How Does Wind Turbine Noise Affect People? Acoustics Today, Winter, 20-28.

[8] Hubbard, H.H. (1982) Noise Induced House Vibrations and Human Perception. Noise Control Engineering Journal, 19, 49-55. https://doi.org/10.3397/1.2827592 
[9] Kelley, M.C. and Garstang, M. (2013) On the Possible Detection of Lightning Storms by Elephants. Animals, 3, 349-355. https://doi.org/10.3390/ani3020349

[10] Ledley, F.D. (1982) Evolution and the Human Tail: A Case Report. The New England Journal of Medicine, 306, 1212-1215. https://doi.org/10.1056/NEJM198205203062006

[11] Nimura, Y. and Nei, M. (2003) Evolution of Olfactory Receptor Genes in the Human Genome. Proceedings of the National Academy of Sciences of the United States of America, 100, 12235-12240. https://doi.org/10.1073/pnas.1635157100

[12] World Health Organisation (2009) Night Noise Guidelines for Europe. WHO Regional Office for Europe, Copenhagen.

[13] Boselli, M., Parrino, L., Smerieri, A. and Terzano, M.G. (1998) Effect of Age on EEG Arousals in Normal Sleep. Sleep, 21, 351-357.

[14] World Health Organisation (2011) Burden of Disease from Environmental Noise: Quantification of Healthy Life Years Lost in Europe. WHO Regional Office for Europe, Copenhagen.

[15] Fields, J.M., De Jong, R.G., Gjestland, T., et al. (2001) Standardized General-Purpose Reaction Noise Questions for Community Noise Surveys: Research and a Recommendation. Journal of Sound and Vibration, 242, 641-679.

[16] Ohrstrom, E., Skanberg, A., Svensson, H. and Gidlof-Gunnarsson, A. (2006) Effects of Road Traffic Noise and the Benefit of Access to Quietness. Journal of Sound and Vibration, 295, 40-59.

[17] Hume, K.I., Brink, M. and Basner, M. (2012) Effects of Environmental Noise on Sleep. Noise \& Health, 14, 297-302.

[18] He, Q., Zhang, P., Li, G., Dai, H. and Shi, J. (2017) The Association between Insomnia Symptoms and Risk of Cardio-Cerebral Vascular Events: A Meta-Analysis of Prospective Cohort Studies. European Journal of Preventive Cardiology. https://doi.org/10.1177/2047487317702043

[19] Chung, S.A., Wolf, T.K. and Shapiro, C.M. (2009) Sleep and Health Consequences of Shift Work in Women. Journal of Women's Health, 18, 965-977. https://doi.org/10.1089/jwh.2007.0742

[20] Carter, P.J., Taylor, B.J., Williams, S.M. and Taylor, R.W. (2011) Longitudinal Analysis of Sleep in Relation to BMI and Body Fat in Children: The FLAME Study. BMJ, 342, d2712. https://doi.org/10.1136/bmj.d2712

[21] Hanlon, E.C., Tasal, E., Leproult, R., et al. ((2016) Sleep Restriction Enhances the Daily Rhythm of Circulating Levels of Endocannabinoid 2-Arachidonoglycerol. Sleep, 39, 653-664. https://doi.org/10.5665/sleep.5546

[22] Xie, L., Kang, H., Xu, Q., et al. (2013) Sleep Drives Metabolite Clearance from the Adult Brain. Science, 342, 373-377. https://doi.org/10.1126/science.1241224

[23] Yang, G., Lai, C.S.W., Cichon, J., Ma, L., Li, W. and Gan, W.-B. (2014) Sleep Promotes Branch-Specific Formation of Dendritic Spines after Learning. Science, 344, 1173-1178. https://doi.org/10.1126/science. 1249098

[24] Sexton, E.S., Storsve, A.B., Walhovd, K.B., Johansen-berg, H. and Fjell, A.M. (2014) Poor Sleep Quality Is Associated with Increased Cortical Atrophy in CommunityDwelling Adults. Neurology, 83, 967-973. https://doi.org/10.1212/WNL.0000000000000774

[25] Irwin, M.R., Olmstead, M.R. and Carroll, J.E. (2016) Sleep Disturbance, Sleep Duration and Inflammation: A Systematic Review and Meta-Analysis of Cohort Studies and Experimental Sleep Deprivation. Biological Psychiatry, 80, 40-52. https://doi.org/10.1016/j.biopsych.2015.05.014 
[26] Möller-Levet, C.S., Archer, S.N., Bucca, G., et al. (2013) Effects of Insufficient Sleep on Circadian Rhythmicity and Expression Amplitude of the Human Blood Transcriptome. Proceedings of the National Academy of Sciences of the United States of America, 110, E1132-E1141.

[27] Archer, N.A., Laing, E.E., Möller-Levet, C.S., et al. (2014) Mistimed Sleep Disrupts Circadian Regulation of the Human Transcriptome. Proceedings of the National Academy of Sciences of the United States of America, 111, E682-E691. https://doi.org/10.1073/pnas.1316335111

[28] Hansell, L.H., Blangiardo, M., Floud, F., et al. (2013) Aircraft Noise and Cardiovascular Disease near Heathrow Airport in London: Small Area Study. BMJ, 347, 15432.

[29] Greiser, E. and Glaeske, G. (2013) Social and Economic Consequences of NightTime Aircraft Noise in the Vicinity of Frankfurt/Main Airport. Gesundheitswesen, 75, 127-133.

[30] Bartrip, P.W. (2004) History of Asbestos Related Disease. Postgraduate Medical Journal, 80, 72-76.

[31] Hanning, C.D. and Evans, A. (2012) Wind Turbine Noise. BMJ, 344, e1527. https://doi.org/10.1136/bmj.e1527

[32] von Hünerbein, S., Moorhouse, A., Fiumicelli, D. and Baguley, D. (2013) Report on Health Impacts of Wind Turbines. Prepared for Scottish Government by Acoustics Research Centre, University of Salford.

[33] Smith, M.G., Ögren, M., Thorsson, P., Pedersen, E. and Waye, K.P. (2016) Physiological Effects of Wind Turbine Noise on Sleep. Proceedings of the 22nd International Congress on Acoustics, Buenos Aires, 5-9 September 2016, 440.

[34] Onakpoya, I.J., O’Sullivan, J., Thompson, M.J. and Heneghan, C.J. (2015) The Effect of Wind Turbine Noise on Sleep and Quality of Life: A Systematic Review and Meta-Analysis of Observational Studies. Environment International, 82, 1-9.

[35] Laugsand, L.E., Strand, L.B., Platou, C., Vatten, L.J. and Janszky, I. (2013) Insomnia and the Risk of Incident Heart Failure: A Population Study. European Heart Journal, 35, 1382-1393. https://doi.org/10.1093/eurheartj/eht019

[36] Hoevenaar-Blom, M.P., Spijkerman, A.M.W., Kromhout, D. and Verschuren, W.M.M. (2013) Sufficient Sleep Duration Contributes to Lower Cardiovascular Disease Risk in Addition to Four Traditional Lifestyle Factors: The MORGEN Study. European Journal of Preventive Cardiology, 21, 1367-1375. https://doi.org/10.1177/2047487313493057

[37] Hoevenaar-Blom, M.P., Annemieke, M.W., Spijkerman, A.M.W., Kromhout, D., van den Berg, J.F. and Verschuren, W.M.M. (2011) Sleep Duration and Sleep Quality in Relation to 12-Year Cardiovascular Disease Incidence: The MORGEN Study. Sleep, 34, 1487-1492. https://doi.org/10.5665/sleep.1382

[38] Heidt, T., Sager, H.B., Courties, G., et al. (2014) Chronic Variable Stress Activates Hematopoietic Stem Cells. Nature Medicine, 20, 754-758.

[39] Pierpont, N. (2009) Wind Turbine Syndrome: A Report on A Natural Experiment. K Selected Publications, Santa Fe, New Mexico.

[40] Sivertsen, B., Lalluka, T., Salo, P., et al. (2014) Insomnia as a Risk Factor for Ill Health: Results from the Large Population-Based Prospective HUNT Study in Norway. Journal of Sleep Research, 23, 124-132. https://doi.org/10.1111/jsr.12102

[41] Salt, A.N. and Lichtenhan, J.T. (2011) Responses of the Inner Ear to Infrasound. IVth International Meeting on Wind Turbine Noise, Rome, Italy.

[42] Schomer, P.D., Edreich, J., Boyle, J. and Pamidighantam, P. (2011) A Proposed 
Theory to Explain Some Adverse Physiological Effects of the Infrasonic Emissions at Some Wind Farm Sites. 5th International Conference on Wind Turbine Noise, Denver, 28-30 August 2013.

[43] Ananthaswamy, A. (2013) Like Clockwork: The Cogs and Wheels That Drive Our Thoughts. New Scientist, 219, 32-35.

[44] Danielsson, A. and Landström, U. (1985) Blood Pressure Changes in Man during Infrasonic Exposure. Acta Medica Scandinavica, 217, 531-535. https://doi.org/10.1111/j.0954-6820.1985.tb03258.x

[45] Nussbaum, D.S. and Reinis, S. (1985) Some Individual Differences in Human Response to Infrasound. University of Toronto Institute for Aerospace Report No. 282, CN ISSN 0082-5225.

[46] International Standards Organisation (1996) Mechanical Vibration and ShockDisturbance to Human Activity and Performance-Classification. 9996, Geneva.

[47] Lawther, A. and Griffin, M.J. (1987) Prediction of the Incidence of Motion Sickness from the Magnitude, Frequency, and Duration of Vertical Oscillation. The Journal of the Acoustical Society of America, 82, 957. https://doi.org/10.1121/1.395295

[48] Castelo Branco, N.A.A., Alves-Pereira, M., Pimenta, A.M. and Ferreira, J.R. (2015) Low Frequency Noise-Induced Pathology: Contributions Provided by the Portuguese Wind Turbine Case. EuroNoise, Maastricht, 31 May-3 June 2015, 1-5.

[49] Mulholland, K.A. (1985) Noise Control. In: Tempest, W., Ed., The Noise Handbook, Academic Press, London, 281-301.

[50] Swinburn, T.K., Hammer, M.S., Richard, J.D. and Neitze, L.L. (2015) Valuing Quiet: An Economic Assessment of U.S. Environmental Noise as a Cardiovascular Health Hazard. American Journal of Preventive Medicine, 49, 345-353. https://doi.org/10.1016/j.amepre.2015.02.016

[51] Götz, T. and Janik, V.M. (2011) Repeated Elicitation of the Acoustic Startle Reflex Leads to Sensitisation in Subsequent Avoidance Behaviour and Induces fear Conditioning. BMC Neuroscience, 12, 30.

http://www.biomedcentral.com/1471-2202/12/30 https://doi.org/10.1186/1471-2202-12-30

[52] Abbassi, M., Zakerian, S.A. and Yousefzadeh, A. (2015) Effect of Wind Turbine Noise on Workers' Sleep Disorder: A Case Study of Manjil Wind Farm in Northern Iran. Fluctuation and Noise Letters, 14, Article ID: 1550020.

[53] Inagaki, T., Li, Y. and Nishi, Y. (2015) Analysis of Aerodynamic Sound Noise Generated by a Large-Scaled Wind Turbine and Its Physiological Evaluation. International Journal of Environmental Science and Technology, 12, 1933-1944. https://doi.org/10.1007/s13762-014-0581-4

[54] Bauer, M., Sander-Thömmes, T., Ihlenfeld, A., Kühn, S., Kühler, R. and Koch, C. (2015) Investigation of Perception at Infrasound Frequencies by Functional Magnetic Resonance Imaging (fMRI) and Magnetoencephalography (MEG). The 22nd International Congress on Sound and Vibration, Florence, $12-16$ July 2015, 1-6.

[55] Cooper, S. (2015) Personal Communication. Batho, W.J.S., Chair (1990) Noise Review Working Party Report. HMSO, London, 27.

[56] Weichenberger, M., Bauer, M., Kühler, R., et al. (2017) Altered Cortical and Subcortical Connectivity due to Infrasound Administered near the Hearing Threshold-Evidence from fMRI. PLOS ONE, 12, e0174420. https://doi.org/10.1371/journal.pone.0174420

[57] Frey, B.J. and Hadden, P.J. (2012) Wind Turbines and Proximity to Homes: The Impact of Wind Turbine Noise on Health: A Review of the Literature \& Discussion 
of the Issues.

http://www.windturbinesyndrome.com/wp-content/uploads/2012/03/Frey_Hadden _WT_noise_health_01Jan2012.pdf

[58] Noise Review Working Party Report (1990) (Batho, W.J.S., Chair). HMSO, London, 27.

[59] Fletcher, H. and Munson, W.A. (1933) Loudness, Its Definition, Measurement and Calculation. The Journal of the Acoustical Society of America, 5, 82-108. https://doi.org/10.1121/1.1915637

[60] James, R.R. (2012) Wind Turbine Infra and Low-Frequency Sound: Warning Signs That Were Not Heard. Bulletin of Science, Technology \& Society, 32, 108-127. https://doi.org/10.1177/0270467611421845

[61] Brüel, P.V. and Oleson, H.P. (1973) Infrasonic Measurements. Inter-Noise, 73, G23z3, Copenhagen, 22-24 August 1973.

[62] Casella Stanger (2001) Report on Low Frequency Noise Technical Research Support for DEFRA Noise Programme. On behalf of DEFRA, Department of the Environment, Northern Ireland, Scottish Executive, National Assembly for Wales.

[63] Kelley, N.D., Hemphill, R.R. and Mckenna, H.E. (1982) A Methodology for Assessment of Wind Turbine Noise Generation. Transactions on ASME, 104, 112-120.

[64] Kelley, N.D., McKenna, H.E., Hemphill, R.R., Etter, C.I., Garrelts, R.I. and Linn, N.C. (1985) Acoustic Noise Associated with the MOD-1 Wind Turbine: Its Source, Impact, and Control. Solar Energy Research Institute, A Division of Midwest Research Institute, Golden, Colorado, USA.

[65] Kelley, N.D. (1987) A Proposed Metric for Assessing the Potential of Community Annoyance from Wind Turbine Low-Frequency Noise Emissions. Presented at the Windpower'87 Conference and Exposition, San Francisco, 5-8 October 1987. Solar Energy Research Institute, A Division of Midwest Research Institute, Colorado, USA.

[66] Bray, W. and James, R. (2011) Dynamic Measurements of Wind Turbine Acoustic Signals, Employing Sound Quality Engineering Methods Considering the Time and Frequency Sensitivities of Human Perception. Proceedings of Noise-Con, Portland, Oregon, 25-27 July 2011.

[67] Kugler, K., Wiegrebe, L., Grothe, B., et al. (2014) Low-Frequency Sound Affects Active Micromechanics in the Human Inner Ear. Royal Society Open Science, 1, Article ID: 140166 . https://doi.org/10.1098/rsos.140166

[68] Department of Trade and Industry (2003) Our Energy Future-Creating a Low Carbon Economy. HMSO, London.

[69] The Working Group on Noise from Wind Farms (1996) The Assessment and Rating of Noise from Windfarms. ETSU-R-97 Final Report, Department of Trade and Industry.

[70] Hessler, G., Leventhall, L.G., Schomer, P. and Walker, B. (2017) Health Effects from Wind Turbine Low Frequency Noise \& Infrasound: Do Wind Turbines Make People Sick? That Is the Issue. Sound \& Vibration, 34-44.

[71] Schmidt, J.H. and Klokker, M. (2014) Health Effects Related to Wind Turbine Noise Exposure: A Systematic Review. PLoS ONE, 9, e114183. https://doi.org/10.1371/journal.pone.0114183

[72] Marshall Day Acoustics (2013) Examination of the Significance of Noise in Relation to Onshore Wind Farms. Commissioned by Sustainable Energy Authority of Ireland (SEAI), 29 November, 29.

[73] Møller, H. and Pedersen, C.S. (2011) Low-Frequency Noise from Large Wind Tur- 
bines. The Journal of the Acoustical Society of America, 129, 3727-3744. https://doi.org/10.1121/1.3543957

[74] Environment, Community and Local Government (2013) Proposed Revisions to Wind Energy Guidelines 2006: Targeted Review in Relation to Noise, Proximity and Shadow Flicker. 11 December 2013.

[75] Kamperman, G.W. and James, R. (2008) The "How To" Guide to Siting Wind Turbines to Prevent Health Risks from Sound.

http://www.windturbinesyndrome.com/wp-content/uploads/2008/10/kamperman-j ames-8-26-08-report-43-pp.pdf

[76] Huson, L. (2015) Stationary Wind Turbine Infrasound Emissions and Propagation Loss Measurements (Paper I). 6th International Conference on Wind Turbine Noise, Glasgow, 20-23 April 2015.

[77] Scientific Committee on Emerging and Newly Identified Health Risks (SCENIHR). Potential Health Effects of Exposure to Electromagnetic Fields (2015) European Commission, Brussels, Belgium.

http://ec.europa.eu/health/scientific_committees/emerging/docs/scenihr_o_041.pdf

[78] Agnew, R.C.N., Smith, V.J. and Fowhes, R.C. (2016) Wind Turbines Cause Chronic Stress in Badgers (Meles meles) in Bitain. Journal of Wildlife Diseases, 52, 459-467.

[79] Karwowska, M., Mikolajczak, J., Dolatowski, Z.J. and Borowski, S. (2015) The Effect of Varying Distances from the Wind Turbine on Meat Quality of GrowingFinishing Pigs. Annals of Animal Science, 15, 1043-1054.

https://doi.org/10.1515/aoas-2015-0051

[80] Pine, M.K., Jeffs, A.G. and Radford, C.A. (2012) Turbine Sound May Influence the Metamorphosis Behaviour of Estuarine Crab Megalopae. PLoS ONE, 7, e51790. https://doi.org/10.1371/journal.pone.0051790

[81] Hassanien, R.H.E., Hou, T., Li, Y. and Li, B. (2013) Advances in Effects of Sound Waves in Plants. Journal of Integrative Agriculture, 13, 335-348.

[82] Carruthers, B.M., van de Sande, M.I., De Meirleir, K.L., et al. (2011) Myalgic Encephalomyelitis: International Consensus Criteria. Journal of Internal Medicine, 270, 327-338. https://doi.org/10.1111/j.1365-2796.2011.02428.x

[83] Surgeon General (2010) How Tobacco Smoke Causes Disease: The Biology and Behavioral Basis for Smoking-Attributable Disease: A Report of the Surgeon General (3. Chemistry and Toxicology of Cigarette Smoke and Biomarkers of Exposure and Harm). Centers for Disease Control and Prevention (US), National Center for Chronic Disease Prevention and Health Promotion (US), Office on Smoking and Health (US), Atlanta (GA).

[84] Department of Energy and Climate Change (2016) Wind Turbine AM Review: Phase 2 Report. WSP/Parsons Brinckerhoff, Bristol.

[85] Miller, L.M., Brunsell, N.A., Mechem, D.B., et al. (2016) Two Methods for Estimating Limits to Large-Scale Wind Power Generation. Proceedings of the National Academy of Sciences of the United States of America, 112, 11169-11174.

https://doi.org/10.1073/pnas.1408251112

[86] Swinbanks, M.A. (2015) Direct Experience of Low Frequency Noise and Infrasound within a Windfarm Community. 6th International Meeting on Wind Turbine Noise, Glasgow, 20-23 April 2015.

[87] Underwood, E.A. (1949) Edward Jenner: The Man and His Work. BMJ, 1, 881-884.

[88] Seldin, M.M., Byerly, M.S., Petersen, P.S., et al. (2014) Seasonal Oscillation of LiverDerived Hibernation Protein Complex in the Central Nervous System of NonHibernating Mammals. Journal of Experimental Biology, 217, 2667-2679. 
[89] Dalgard, C., Eidelman, O., Jozwik, C., et al. (2017) The MCP-4/MCP-1 Ratio in Plasma Is a Candidate Circadian Biomarker for Chronic Post-Traumatic Stress Disorder. Translational Psychiatry, 7, e0125. https://doi.org/10.1038/tp.2016.285

[90] Mapei, C. (MDCCCLVI) Italy, Classical, Historical and Picturesque. Blackie, Glasgow and London, 59-60.

[91] Rosen, G. (1953) Cameralism and the Concept of Medical Police. Bulletin of the History of Medicine, 27, 21-42.

[92] Crew, F.A.E. (1949) Social Medicine as an Academic Discipline. In Massey, A., Ed., Modern Trends in Public Health, Butterworth, London, 46-79.

[93] Blaney, R. (1984) Henry Maunsell (1806-1879): An Early Community Physician. Irish Journal of Medical Science, 153, 42-43. https://doi.org/10.1007/bf02940522

[94] Chadwick, E. (1829) Preventive Police. London Review I, 252-308.

[95] Hamlin, C. (1998) Public Health and Social Justice in the Age of Chadwick: Britain 1800-1854. Cambridge University Press, Cambridge, 1-15.

[96] Coughlin, S.S., Beauchamp, T.L. and Weed, D.L. (2009) Ethics and Epidemiology. Oxford University Press, Oxford, 5-6. https://doi.org/10.1093/acprof:oso/9780195322934.001.0001

[97] Evans, A. (2001) Benjamin Guy Babington: Founding President of the London Epidemiological Society. International Journal of Epidemiology, 30, 226-230. https://doi.org/10.1093/ije/30.2.226

[98] Belongia, E.A. and Naleway, A.L. (2003) Smallpox Vaccine: The Good, the Bad, and the Ugly. Clinical Medicine \& Research, 1, 87-92. https://doi.org/10.3121/cmr.1.2.87

[99] Jasanoff, S. (2012) The Politics of Public Reason. In: Rubio, F.D. and Baert, P., Eds., The Politics of Knowledge, Routledge, Oxford, 11-32.

[100] Zander, J. (2010) The Precautionary Principle in EU Law. In: The Application of the Precautionary Principle in Practice: Comparative Dimensions, Cambridge University Press, Cambridge, 76-151. https://doi.org/10.1017/CBO9780511779862.006

[101] Gill, N., Spencer, Y., Richard-Loendt, A., et al. (2013) Prevalent Abnormal Prion Protein in Human Appendices after Bovine Spongiform Encephalopathy Epizootic Large Scale Survey. BMJ, 347, 15675.

[102] Royal Society of Public Health (2016) Waking up to the Health Benefits of Sleep. University of Oxford, Oxford.

[103] Nightingale F. (1859) Notes on Nursing: What It Is, and What It Is Not. Harrison, London, 27.

[104] Garcia, M.J. (2009) U.N. Convention against Torture (CAT): Overview and Application to Interrogation Techniques. CRS Report for Congress, 26 March 2009, 21.

[105] Ferriter, D. (2014) The Hooded Men. The Irish Times, 6 December 2014.

[106] Punch, J.L. and James, R.R. (2016) Wind Turbine Noise and Human Health: A Four-Decade History of Evidence That Wind Turbines Pose Risks. https://docs.wind-watch.org/Punch-James-Wind-Turbine-Noise-16-10-21.pdf

[107] http://aefweb.info/data/AUSWEA-2004conference.pdf

[108] https://qmail.qub.ac.uk/owa/redir.aspx?C=ypzjvMYSs8dqquKCSrN5yb_3wZ6Bkxx kz1VRQh9Eog32ntjUe2vUCA..\&URL=http\%3a\%2f\%2fwind2050.dk

[109] O’Sullivan, C. (2014) Senior Doctor Defends Wind Turbine Syndrome Conclusions. The Irish Examiner, 6 March 2014.

[110] Baliatsas, C., van Kamp, I., van Poll, R. and Yzermans, J. (2016) Health Effects from Low-Frequency Noise and Infrasound in the General Population: Is It Time to Lis- 
ten? A Systematic Review of Observational Studies. Science of the Total Environment, 557-558, 163-169.

[111] Spector, B. (1963) Jeremy Bentham 1748-1832: His Influence upon Medical Thought and Legislation. Bulletin of the History of Medicine, 33, 25-42.

[112] U.S. Environmental Protection Agency (1974) Information on Levels of Environmental Noise Requisite to Protect Public Health and Welfare with an Adequate Margin of Safety. Washington DC, 550/9-74-004.

[113] Hughes, G. (2012) The Performance of Wind Farms in United Kingdom and Denmark. Renewable Energy Foundation, London.

[114] Hughes, G. (2012) Why Is Wind Power So Expensive? An Economic Analysis. The Global Warming Policy Foundation, GWPF Report 7.

Submit or recommend next manuscript to SCIRP and we will provide best service for you:

Accepting pre-submission inquiries through Email, Facebook, LinkedIn, Twitter, etc. A wide selection of journals (inclusive of 9 subjects, more than 200 journals)

Providing 24-hour high-quality service

User-friendly online submission system

Fair and swift peer-review system

Efficient typesetting and proofreading procedure

Display of the result of downloads and visits, as well as the number of cited articles Maximum dissemination of your research work

Submit your manuscript at: http://papersubmission.scirp.org/

Or contact jss@scirp.org 